may be "grey" rather than "black", so that the quostion of solar oblateness and the real magnitude of the residue in the perihelion rotation of Mercury is at present of over. riding significance as a test to distinguish between the two theories, although sufficiently accurate measurements of the gravitational bending of light may shortly provide an independent test. There is no attempt to gloss over the difficulties involved with each kind of experiment, although naturally Dicke is not an unbiased reporter, and this book provides a useful insight into the way in which cosmologists, solar astronomers and laboratory physicists can all contribute to an investigation of the gravitational interaction.

Suitable for the non-specialist or student rather than those working directly on these problems, the monograph is cxcellent value, being lavishly illustrated and generally well produced apart from a few minor misprints.

JoHN GRIBBIN

\title{
Obituaries
}

\section{Dr D. F. Martyn}

THE death of David Forbes Martyn on March 6 has removed a pioneer of research on the upper atmosphere and a leader of Australian science. He was born on June 17, 1906, in Cambuslang, Scotland, the son of Dr Somerville Martyn. His early education at Plymouth College and Allan Glen's School was followed by a period at the Royal College of Science, London, from which he graduated BSe, ARCSe, in 1926. $\mathrm{He}$ took his $\mathrm{PhD}$ in 1929 , and in 1936 was awarded the degree of DSc by the University of London. He was Houldsworth Fellow of the University of Glasgow from 1927 to 1929.

In 1929 Martyn moved to Australia, to a post with the Radio Research Board, which was attached to Mount Stromlo Observatory, Canberra. This was later incorporated into the Commonwealth Seientific and Industrial Research Organization (CSIRO), and at the time of his death he was chief officer of the CSIRO Upper Atmosphere Section.

In 1936 Martyn reconciled a number of apparently conflicting observational results by providing a remarkable model of the upper atmosphere. Ho showed that, although there is a warmer region above the stratosphere, the temperature must drop again to a very low value (about $160 \mathrm{~K}$ ) at $82 \mathrm{~km}$ and then rise to very high values (about $1,000 \mathrm{~K}$ ) at heights above $250 \mathrm{~km}$. $\mathrm{He}$ also concluded that tho gases at such heights woro fully mixed by winds and so consisted mainly of nitrogen. These results have since been amply confirmed.

Before the second World War he also collaborated in a number of ionospheric problems including the basis of the theory of interaction of radio waves and the polarization of downcoming radio waves. After the war ho continued these studies, discovering the existence of large semidiurnal lunar oscillations in the height and electron density of the ionospheric $\mathrm{F}$ region. He showed that the oscillations are tho result, not of local winds, but of electrodynamic drifts caused by clectric fields generated in the lower "dynamo" or E region and communicated upwards along tho highly conducting geomagnetic ficld lines. Martyn was the first to give a clear outline of the morpho$\log y$ of ionosphcric "storms" and to show that they develop almost simultaneously all over the globe according to a relatively simple pattern when cxpressed in geomagnetic time.

In 1948 Martyn attacked the long outstanding problem of the dynamo theory of the daily geomagnetic variations. The known tidal velocities and electrical conductivity in the ionosphere are inadequate to explain these variations. Martyn suggested that Hall conductivity might remove the discrepancy and later, in collaboration, developed a full theory. He contributed also to the theory of radio emission from the Sun.

Immediately before the Second World War, Martyn was sent to Britain by the Commonwealth Government to learn the secrets of radar. On his return he became the first chief of the Radiophysics Laboratory of CSIRO,

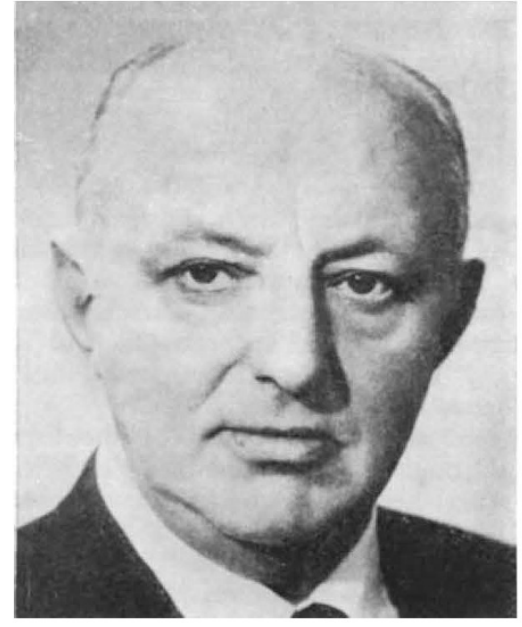

where he started radar development in Australia. As director of operational research for the Australian fighting services from 1942 to 1944 he took an important part in the war in the Pacific.

Martyn's greatest contribution to scionce in Australia was probably his role in the foundation of the Australian Academy of Science. As one of the Fellows of the Royal Society resident in Australia who initiated and carried through this difficult task, he worked indefatigably, with great patience and tact, never allowing the many personal and practical difficulties to dampen his enthusiasm. It was Martyn who as first Secretary (Physical Sciences) produced from the proposals mado by his colleagues the statutes and rules, on the basis of which a Royal Charter was presented to the founding fellows by the Queen, during her visit to Canberra in 1954. He was president when he died.

Martyn was chairman of the Australian National Committee for Space Research and the United Nations Scientific and Technical Committee on the Peaceful Uses of Outer Space. He served with URSI as chairman of the Radio Astronomy Commission and as chairman of the Ionosphere Commission. He was awarded the Chree Medal of tho Physical Society of London in 1954, the Lyle Medal of the Australian National Research Council in 1947, the Sidey Medal of the Royal Society of New Zcaland in 1947 and the Burfitt Medal of the Royal Society of NSW in 1950, and his contributions to science were recognized by other leamed societies. He was elocted to the Royal Society in 1950 .

David Martyn was a mar of strong convictions, held tenaciously and often pugnaciously, so that his friendships and his enmities brought him troubles and anxioties. He fought fearlessly for integrity and high standards in science. He is survived by his widow whom he married in 1944. 